\title{
Agricultural settlement and soil quality in the Brazilian Amazon
}

\author{
Marcia C. Castro • Burton H. Singer
}

Published online: 25 December 2011

(C) The Author(s) 2011. This article is published with open access at Springerlink.com

\begin{abstract}
This paper discusses the implications of poor or non-existent information on soil quality, at the proper scale, during the planning and implementation of settlement projects in the Brazilian Amazon. Based on data from the Machadinho settlement project, Rondônia, we show that most settlers had no knowledge about the agricultural capability of the area, did not receive technical information, could not afford agricultural inputs, planted inadequate crops in the early years of occupation, and did not manage to stay in their plot for a long period of time. Satellite images indicated that patches of land with good soil quality were not necessarily the first to be utilized. Inadequately planned settlements face many challenges (poor soil being one of them) and are likely to result in land turnover, conversion of land into pasture, land concentration among wealthier persons, invasion of areas by poorer people, and deforestation, defying the main purpose of agrarian reform.
\end{abstract}

Keywords Soil quality $\cdot$ Settlement projects $\cdot$ Brazilian Amazon $\cdot$ Agrarian reform

\section{Introduction}

Daniel Hogan was instrumental in enriching the demography-environment research interface in Brazil, going well beyond the traditional Malthusian debates. Among the topics he promoted was migration, the establishment of settlements and ensuing urbanization, and understanding of the factors that facilitated sustainable land use (Hogan 1992, 1995, 2005, 2007; Hogan et al. 2002; Hogan and Ojima 2008).

\footnotetext{
M. C. Castro $(\varangle)$

Department of Global Health and Population, Harvard School of Public Health, 665 Huntington Avenue, Bldg. I, Room 1113, Boston, MA 02115, USA

e-mail: mcastro@hsph.harvard.edu

B. H. Singer

Emerging Pathogens Institute, University of Florida, Gainesville, FL, USA
} 
The large agricultural emphasis among new migrants to the legal Amazon placed the assessment and proper utilization of soils as a fundamental component of land use transformation.

Consistent with Daniel Hogan's promotion of much greater emphasis on population distribution, rather than just growth, and an associated emphasis on local environmental consequences (Hogan et al. 2002), we focus on large-scale efforts of human settlement in the Brazilian Amazon that started in the 1970s. Settlements were either directed (organized by private or governmental initiatives) or spontaneous, and varied in many different aspects, including availability of resources (technical and financial), average size of the plot, soil quality, provision of infrastructure and services, and characteristics of settlers. The outcome of the settlement is often related to a myriad of social, economic, environmental, political, and demographic factors, acting at varied scales (Browder 2002). Among the positive outcomes are increased agricultural production, reduction in the number of landless people, and potential reduction of inequality of land distribution. However, among the negative outcomes are land disputes and turnover, disease outbreaks, and rapid deforestation (Almeida 1992; Brondízio et al. 2002; Sawyer and Sawyer 1987; Wood 2002).

Guanziroli et al. (1999) suggested that factors related to the natural characteristics of the area are the most important determinants of settlement development. Among these factors, soil fertility, elevation, and presence of water play a crucial role. Use of land for pasture in settlement areas has been associated with poor soils, availability of water, and access to credit for agriculture (McCracken et al. 2002). In addition, an analysis of five sites in the Amazon showed that areas with better soil had higher rates of secondary succession growth, lower rates of land turnover, higher diversity in land use, and higher income accumulation (Moran et al. 2002). Thus, planning of new settlement areas should be made based on information of local characteristics at a fine grained spatial scale. This would allow for decision making at the plot level, indicating the feasibility of the settlement project, and facilitating the assessment of agricultural capability and carrying capacity (Fearnside 1986a). That information should also be used during the implementation of the project in the form of technical support provided to new settlers (Moran et al. 2002).

Most Amazonian soils are weathered and lack good fertility (Hecht and Cockburn 1989; Jordan 1985). More than 75\% need chemical inputs and technological management in order to promote sustainable annual cropping. It has been estimated that only $7 \%$ of the soils in the Amazon have no major agricultural limitations (Cochrane and Sanchez 1982). Therefore, when a settlement area with substandard soil quality is opened for occupation, major social and environmental burdens can be anticipated. First, farmers do not know the potential of the land, the ideal crops to be planted, and the practices to be used, but, most importantly, they do not know that the land has restricted potential for long-term sustainable agricultural production. Second, failure to make the land productive may result in deforestation levels beyond initial expectations, and eventual land turnover and use for pasture. 
Nevertheless, comprehensive assessments of soil quality at a fine scale that could inform planning activities_-ideally 1:20,000 or 1:10,000 (Moran 1990)—were not available prior to approval of new agricultural settlements (Fearnside 1989) and before roads had been opened (Almeida 1992). Information at a regional scale $(1: 1,000,000)$ was assembled during the 1970s, and land utilization maps were produced based on a concept of "ideal land", which considered soils with high natural fertility, no deficiency of water and oxygen, no susceptibility to erosion processes, and no impediments to mechanization (RADAMBRASIL 1978). The millionth scale, however, does not allow decision making at a farm level, and the use of those maps for planning new settlement areas neglected to account for local variability and exaggerated the quality of the soil (Moran 1990). Despite other numerous soil quality assessments carried out under government auspices, the requisite knowledge of the findings rarely made their way to migrants who could have greatly benefitted from it.

As a direct follow on to Hogan's broad-based discussion of sustainable development (Hogan 2005), this paper utilizes detailed information of soil characteristics assembled for a settlement project in the western Amazon, to discuss the process of plot allocation, occupation, and land use. It also appraises possible relationships between soil quality and land turnover and use of the land for pasture, discussing the findings in the context of sustainable agriculture production in the Amazon region and of effective agrarian reform. It does so in greater detail and in a substantially more integrative fashion than much of the extant literature.

The remainder of this paper is organized into four sections. We start with a summary of the process of agricultural settlement in the Brazilian Amazon and of the frameworks proposed to evaluate its success. The following section describes the study area, the data used, and the analytical methods. The fourth section presents the results, followed by a discussion section that focuses on challenges for future sustainable settlement in the Amazon.

\section{Agricultural settlement in the Amazon}

Since the European discovery of Brazil in 1500, the Amazon had periods of rapid population increase and depopulation. Migration was a major component in this changing demography, stimulated by economic opportunities and government interventions. The last period started around World War II (Benchimol 1985) and culminated with large-scale efforts to occupy the region that started in the 1970s (Almeida 1992). Many regional development programs were launched, which promoted the opening of new settlement areas through the distribution of forested land for agriculture colonization (Becker 2001; Sparovek 2003). These programs were often associated with high deforestation, and a major attempt to integrate settlement efforts and environmental preservation was taken in 2001, when Conselho Nacional do Meio Ambiente-CONAMA (National Environment Council) passed legislation demanding two licenses for the establishment of new settlement projects. The first, issued during the planning phase of the project, approves the location and design, and attests to its environmental feasibility based 
on detailed assessment reports. The second authorizes the opening of the area for occupation, given that any necessary mitigation measures are in place. All projects implemented before the approval of this legislation needed to have a second license issued. Projects located in the Amazon also need an evaluation of the susceptibility of the area to malaria transmission. Effective implementation of the legislation, however, has been far from ideal. A recent study revealed that less than $10 \%$ of all settlement projects implemented in Brazil (more than 7,000) have the required occupation license (Araújo 2006).

Many factors play a role in decisions about land use and therefore contribute to the pattern of environmental change that take place in settlement areas. Those factors can be grouped as: (1) internal factors that encompass political, social, demographic and economic issues-e.g., household composition, income, network support, distance to markets, educational level, affiliation to unions and associations, technical knowledge, health, length of residence, and plot size; (2) local external factors-e.g., soil quality, land prices, infrastructure and services, support organizations, and storage facilities; (3) regional external factors-e.g., distance to markets, transportation, availability of incentives and credit, and land use regulations; and (4) national external factors-e.g., crop prices, subsidized credit, market prices, and environmental policy (Browder 2002).

This level of detail in discussing environmental change was advocated in Daniel Hogan's prospectus for integrating a more nuanced approach to demography in the now ongoing programs operating under the umbrella of 'Human Dimensions of Global Environmental Change' (Hogan 2007). It is also central to Hogan's treatment of the interface between population dynamics and sustainability (Hogan 2009).

\section{Framework for measuring success}

Evaluations of settlement projects often take place shortly after they are initiated (i.e., within 5 years), which is likely to exaggerate immediate effects and ignore those that take time to appear. The social, economic, and political dynamics involved in these projects takes much longer to unfold, and the short-term evaluations can be very much at odds with the evidence from longer term follow-up (Almeida 1992; Cliggett et al. 2007; Salamon 1979). While in the early years of settlement, success often depends mainly on farmer's knowledge, as time progresses success tends to be related with farmer's ability to benefit from local opportunities (Almeida 1992). For example, accurate perceptions of soil fertility have been associated with settler's origin, length of time in the settlement area, and information previously received (Muchagata and Brown 2000). In summary, the success of the project depends on how the adaptation process of farmers to the new environment takes place over time (Moran 1989a). With regard to duration of follow-up needed to support a claim of success, or the lack thereof, of a settlement program, Scudder (2006) advocates examination of living standards and community well-being in the second generation following the opening of an area for settlement.

The importance of time in evaluations of settlement efforts was emphasized by a 4-stage model of colonization proposed by Moran (1989a, b): (1) planning phase, 
including the construction of roads and recruitment of settlers; (2) early stages of colonization (first 5 years), when settlers tend to reproduce their previous farming knowledge, and go through a learning-and-adapting process; (3) experimentation phase (5-10 years into the colonization process), when land turnover tends to intensify and initially successful farmers may achieve higher levels of productivity; and (4) consolidation phase (10 years after the colonization started), when governmental interference in the area becomes reduced. Measuring success at the early stages will tend to produce negative evaluations, while a completely different outcome is expected at the consolidation phase.

A comprehensive study assessed the quality of settlement projects established in Brazil between 1985 and 2001. The study included the opinion of government officials, settlers, and local organizations, and proposed the creation of indices that could facilitate a comparative analysis of settlement programs across the country. Five indices were selected (Sparovek 2003): (1) efficacy of land reorganizationconsidered the success in settling the planned number of families, and evaluated land turnover and land concentration; (2) quality of life-evaluated housing conditions, and access to water, sanitation, electricity, transportation, schools, and basic health care; (3) social organization-evaluated the existence of community associations and collaborative initiatives with the potential to help settlers resolve problems of access to services, benefits, and market opportunities; (4) environmental preservation-assessed the degree of preservation of protected areas, the extent of illegal extractive activities, and the existence of activities toward minimizing erosion and land degradation; and (5) operational strategy-evaluated the extent to which the government provided what was planned from the time of initial implementation until the consolidation of the settlement project: credit, land title, and varied infrastructure (e.g., water, electricity, road access). The study concluded that the effectiveness of settlement efforts showed significant regional differences. In the north region, ${ }^{1}$ projects had soils with quality below the national average, there were a significant number of abandoned plots, land concentration was high, overall quality of life was lower, and environment-related indicators were not favorable compared to other regions (Sparovek 2003).

Different factors have been proposed as potential modifiers to aid the successful development of settlement areas, but five were selected as critical barriers. They are, in order of importance, the local ecology (e.g., elevation and soil quality), precarious infrastructure, lack of technical assistance, lack of productive and political organization among the settlers, and delayed or absence of access to credit (Guanziroli et al. 1999). Therefore, the selection of areas for the establishment of new settlements is of utmost importance. Opening of areas that have poor soil quality imperils the development of the settlement, imposes a huge burden on settlers, and results in projects that are economically, environmentally, and socially unsustainable (Almeida 1992). Indeed, results from the First Agrarian Reform Census conducted in 1996 revealed many problems such as low percentage of occupancy, land concentration, and illegal deforestation (Incra/Crub/Unb 1997a).

\footnotetext{
1 The Brazilian Amazon is comprised of all the states of the North region, one state from the Center-West region (Mato Grosso) and most of Maranhão state (west of longitude $44^{\circ}$ ), located in the northeast region.
} 
The most appropriate approach to evaluate success of settlement efforts is beyond the scope of this paper and is a topic for further debate. While a somewhat simpler alternative is to consider initial goals and appraise the extent to which they were achieved over a certain time period, a more elaborated strategy would consider a multidisciplinary approach, evaluating social, economic, and environmental impacts of the project, through a comprehensive cost-benefit analysis.

\section{Methods}

\section{Study area}

The Machadinho settlement project is located in the western part of the Brazilian Amazon, in the northeast portion of Rondônia State. It was promoted by the Programa Integrado de Desenvolvimento do Noroeste do Brasil-POLONOROESTE (Northwest Region Integrated Development Program), co-sponsored by the Brazilian government and the World Bank (1981). Although six tracts were initially planned, only four were included in the final plans, given the poor quality of soils evaluated at a millionth scale (INCRA 1991). Machadinho was the first colonization project that incorporated a detailed plan of action to prevent the most harmful consequences of frontier expansion previously observed in the Amazon (Sawyer and Sawyer 1987). That plan included an original and carefully planned plot design (average plot size was 40 ha), accounting for the local topography and hydrology, avoiding the usual and often inefficient fishbone pattern; the construction of auxiliary roads, schools, health units, governmental agencies involved in rural development, forestry control posts, commercial and recreational areas; land use planning; execution of complementary soil analyses; provision of financial support for the acquisition of seeds and initial equipment; building of crop drying and storage in accordance with the local climatic and agricultural conditions; protection of natural parks and reserves, water sources, and consideration of endangered species; acquisition of all necessary equipment for schools; establishment of community organization; and a comprehensive health project with three main goals: strengthen malaria control, set up a network of health care facilities, and stimulate research (World Bank 1992). Despite all the planning, flaws in the implementation processes, combined with adverse economic conditions that hit Brazil in the 1980s, resulted in major social, environmental, and health problems in Machadinho (Monte-Mór 1997). Technical and financial supports to new settlers were compromised. Except for roads, construction of all infrastructure was delayed (World Bank 1992).

Survey data

Multiple household surveys were carried out in Tracts 1 and 2 of Machadinho, covering $76 \%$ of what were regarded as occupied plots in 1985 and $100 \%$ of such plots in 1986, 1987, and 1995 (Castro 2002). An occupied plot is one in which settlers cleared some of their land and lived at least part-time (Sawyer 1985). The surveys included questions on health, demographic, economic, social, ecological, 
and agricultural characteristics (Sawyer 1985; Sawyer and Sawyer 1987), and ethnographic assessments were also conducted. We used these data to evaluate patterns of occupation and land use contrasted with soil quality information. All data analyses were done using Stata (Stata Corp., College Station, TX, USA).

\section{Soil assessment data}

Prior to project approval in 1982, the only available information on soil quality for Machadinho was based on the RADAMBRASIL project, which revealed that the majority of the area had restricted agricultural capability (assuming no use of inputs and mechanization), and small patches of land were not appropriate for farming (RADAMBRASIL 1978). Detailed reconnaissance soil surveys were conducted between 1982 and 1984, and used a 1:50,000 scale; although not optimum for planning at the farm level, it is the most detailed information available for the area. The surveys generated a soil taxonomy and provided an assessment of land suitability for agriculture considering types of soil limitation, strategies for improving soil conditions for agriculture, elevation, and level of management. The assessment did not consider the use of irrigation and did not assume pasture as one of the suitable types of land use, since replacing the forest with pasture was considered an irrational choice for the region (Wittern and Conceição 1982). Table 1 summarizes the criteria used in the soil survey.

Agricultural suitability classification included four classes: good, medium, restricted, and inappropriate (areas that should be assigned for preservation), and each class was evaluated for different levels of management. Therefore, some areas could present good quality at a developed management level, but only restricted at a primitive one. In addition, some soils could be unsuitable for agriculture at a particular type of management level.

All maps produced and published by the detailed soil surveys were scanned at a high-resolution, digitized in ArcMap (ESRI, Redlands, CA, USA), and projected to match available spatial data for Machadinho. Using the plot boundaries for Tracts 1 and 2, the area of each type of agricultural suitability, elevation, and soil limitation by plot was calculated. Significant correlation between elevation, soil limitations, plot occupancy and use of the land as pasture was assessed through the Spearman's correlation coefficient. In order to facilitate comparisons at the plot level, we constructed an index as a weighted average of the percentages of each type of agricultural suitability, with weights equal to 0.5 for good, 0.25 for medium, 0.15 for restricted, and 0.05 for soils inappropriate for agriculture or not recommended at the management level. Therefore, the calculated index ranges from 0.05 (worst soils) to 0.5 (best soils). Internal coherence of the index was assessed by testing whether its average value was significantly different at each type of management level, considering a $5 \%$ cutoff.

The soil survey also included suggestions to maximize agricultural output in the initial years of occupation, which would allow farmers to progressively accumulate capital. A slash-and-burn process that takes advantage of timber with commercial value was recommended, but bare soil should not be exposed to the elements for a long period of time to avoid erosion and loss of nutrients. Crop diversification and 
Table 1 Major components considered in the assessment of agricultural suitability

\begin{tabular}{ll}
\hline Component/level & Description \\
\hline $\begin{array}{l}\text { Agricultural management } \\
\text { (A) Primitive }\end{array}$ & $\begin{array}{l}\text { Based on manual work, with very little use of financial and technical } \\
\text { resources. }\end{array}$ \\
(B) Pre-development & $\begin{array}{l}\text { Use of animal traction and modest use of financial and technical resources. } \\
\text { (C) Developed }\end{array}$ \\
$\begin{array}{l}\text { Mechanization is present in all agricultural phases; there is intensive } \\
\text { investment to improve the land, and intensive use of available technical } \\
\text { information. }\end{array}$
\end{tabular}

Soil limitation: (all limitations were classified as absent, low, medium, high, and very high)
Lack of soil fertility If lack of fertility is very high, there are extremely remote changes that the land can be used for agriculture purposes.
Deficiency of water Each class indicates the period of time when the soil would not provide enough water for plants: low $=1-3$ months, medium $=3-6$ months, high $=6-8$ months, and very high $=8-10$ months. The longer the period, the lower the changes that year-long crops can succeed.

Excess of water or lack Indicates the natural draining capacity of the soil. Each class indicates the of oxygen propensity for flooding.

Susceptibility to erosion Intrinsically related to elevation. Each class indicates the need to use inputs: medium susceptibility demands intensive use, high susceptibility requires the use of costly inputs (which often are not cost-effective), and very high is not suitable for agricultural use.

Restrictions to

This limitation only applies to the developed level of management, since the mechanization other two do not imply the use of mechanization. Intrinsically related to elevation-areas with intense terrain oscillations restrict the use of mechanization.

Improvements: (only possible at pre-development and developed levels of management; at primitive levels it was considered that lack of fertility could be improved for up to 3 years as a result of the slashand-burn)

\section{Type 1}

Type 2

Type 3

Elevation

Flat

Slightly hilly

Hilly

Severely hilly

Mountainous

Roughed
Simple techniques with small financial investments.

Intensive and sophisticated methods requiring significant financial investments.

Demands large-scale projects, often beyond the financial capabilities of farmers.

Absence or minimum terrain oscillations.

Terrain oscillations range from 3 to $8 \%$.

Terrain oscillations range from 8 to $20 \%$.

Terrain oscillations range from 20 to $45 \%$.

Terrain oscillations range from 45 to $75 \%$.

Terrain oscillations above $75 \%$.

Source: Wittern and Conceição (1982)

rotation were advised to control plant diseases. Rotation was also suggested in the specific case of cassava, which should not be cultivated in the same area for more than 2 years. Table 2 shows a list of selected crops recommended for each management level. 
Table 2 Recommended crops according to the level of agricultural management

\begin{tabular}{ll}
\hline Management level & Selected crops \\
\hline (A) Primitive & $\begin{array}{r}\text { Cassava, rice, rubber tree, guarana, pineapple, banana, mango, guava, cupuacu, } \\
\text { sapoti, bacuri, graviola, abiu, peach palm, abrico, biriba, mapati, Brazilian nut }\end{array}$ \\
(B) Pre-development & $\begin{array}{r}\text { Maize, beans, soy, sugar cane, sweet potato, coffee, pumpkin squash, melon, } \\
\text { cucumber, chayote, watermelon }\end{array}$ \\
(C) Developed & Cocoa, black pepper
\end{tabular}

Source: Wittern and Conceição (1982)

Remotely sensed data

To evaluate the relationship between soil quality and the clearing process, we utilize information from Landsat 5-Thematic Mapper (TM) satellite images acquired in $08 / 07 / 1985$ and $07 / 15 / 1994$. Unsupervised classification was conducted using bands $3,4,5$, and 7 , in order to extract information of water, forest, and areas where the forest cover had been removed, without attempting to obtain categories of land use in non-forest areas. A layer with the network of streams and rivers in the area was rasterized and combined with the imagery to improve the classification of water bodies. The classification was combined with layers of plot boundaries and of agricultural suitability to produce data on the percentage of cleared area by plot and soil attributes. All imagery analyses were done in IMAGINE (ERDAS, Atlanta, GA, USA).

\section{Results}

\section{Soil characteristics}

Figure 1 shows maps of elevation and soil constraints (as defined in Table 1). The vast majority (95\%) of plots lack adequate soil fertility at some level, which contributed to the reduced number of areas with good agricultural suitability at a primitive level of management. Although most soils unsuitable for agriculture purposes were assigned as protected forest reserves, patches of varied size remained in 96 plots: in 29 of those, the unsuitable soil was adjacent to the road and therefore was likely to be the first to be cleared by the settler. Areas close to streams are prone to flooding during the rainy season (they are represented by the "FO" category in Fig. 1, indicating lack of fertility and oxygen, and excess of water), but given the ecologically sensitive design of Machadinho, they were mostly found in the rear of the plots.

The diversity in agricultural suitability within- and between-management levels is shown in Fig. 2. The most adverse conditions for agriculture were observed at the primitive level of management, which is often the common practice among new settlers. Large within- and between-plot diversity of soils was observed; in some plots, agricultural suitability ranged from good to inappropriate, which represents a 


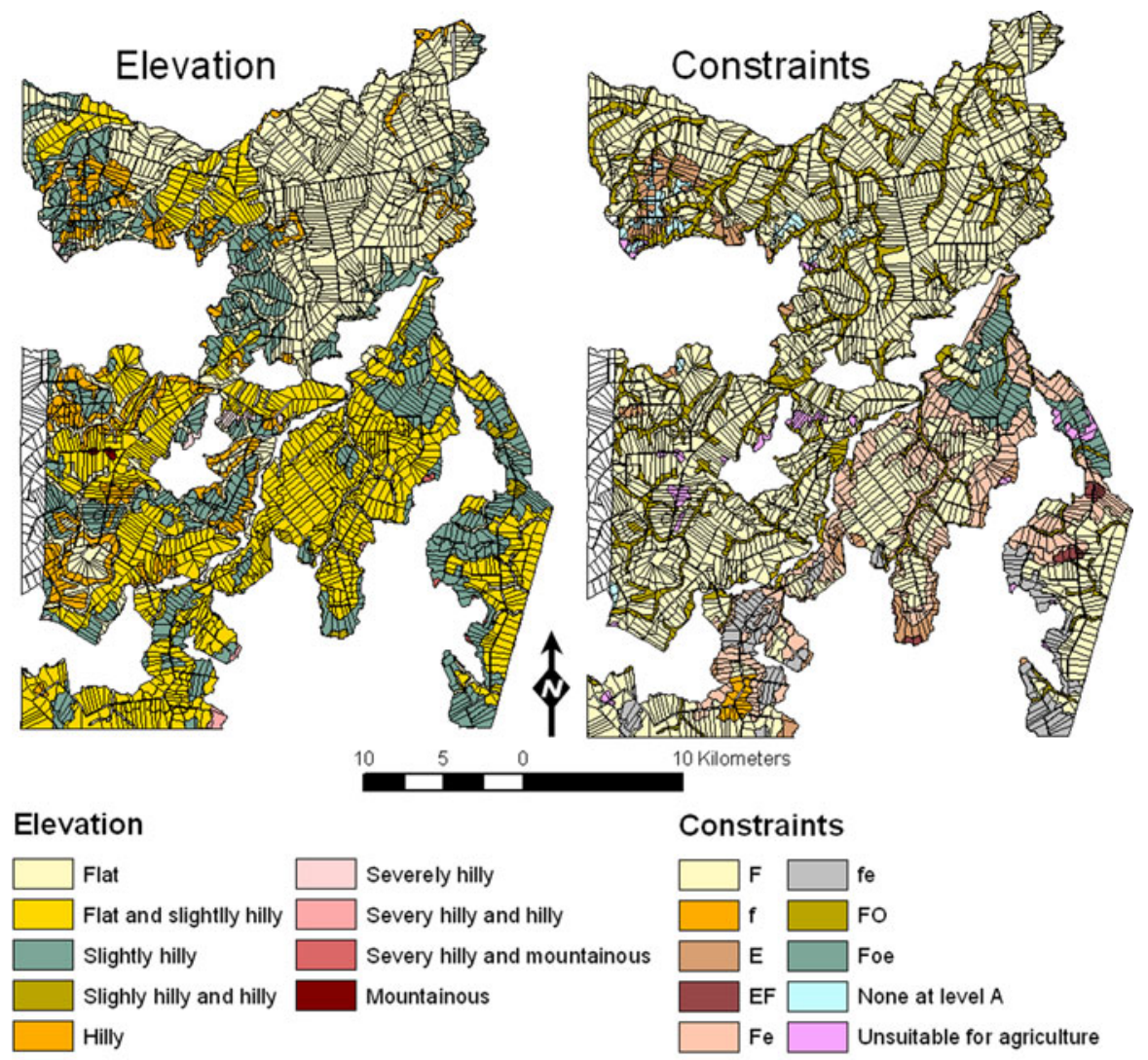

Source: Wittern \& Conceição 1982; INCRA 1984b, 1984c.

Notes:

1. Based on published maps the information on soil quality could be determined for $95.6 \%$ of the plots on Tract 2.

2. The letters F, E, and O used in legend of the soil constraints refer to lack of fertility, susceptibility to erosion, and excess of water/lack of oxygen, respectively. High caps indicate higher constraints levels, while low caps in dicate lower levels.

Fig. 1 Elevation and soil limitations in Machadinho Project, Tracts 1 and 2

challenge. For example, assuming that settlers often start forest clearing near the road, if the best soils were located in the rear of the plot, chances were they would not be used for farming in the initial years of occupation (if ever).

Table 3 shows the index of agricultural suitability. A lower average index for a developed level, compared to a pre-developed level, is justified by impediments to mechanization in areas with irregular elevation. Average values at each management level were significantly different, as shown by non-overlapping 95\% confidence intervals. Based on the index, $94 \%$ of the plots in Tracts 1 and 2 would have improved agricultural suitability if farmers had been able to utilize information about pre-development management potential. That could be achieved by small 


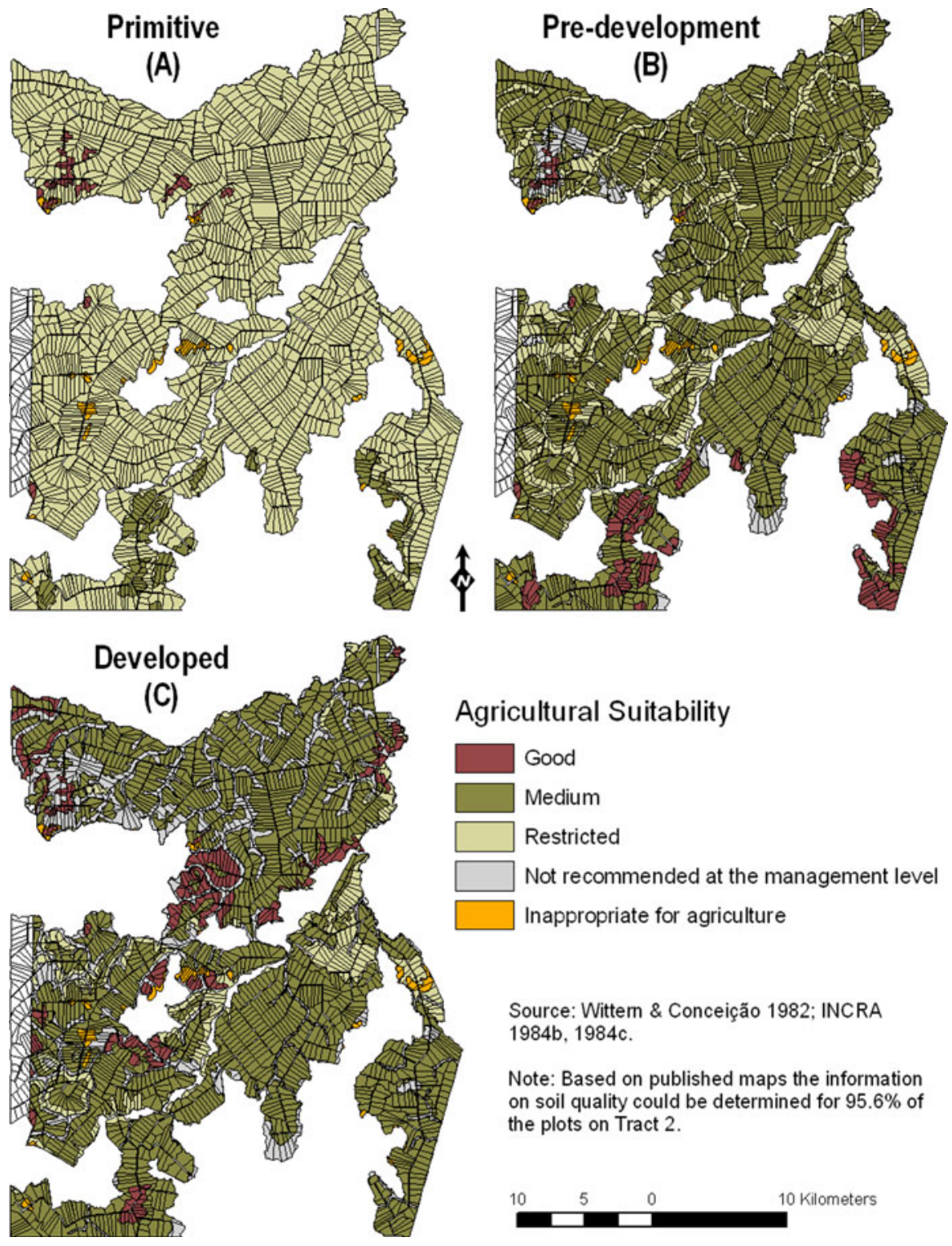

Fig. 2 Agricultural suitability in Machadinho, Tracts 1 and 2, according to different levels of management

financial support that would allow farmers to afford inputs to improve the quality of the land. Although that was part of the planned strategy in Machadinho, it was not effectively put in practice (World Bank 1992). Also, according to the calculated index, only $3.6 \%$ of plots would have the same agricultural potential regardless of the amount of technical and financial inputs used by the farmer. 
Table 3 Index of agricultural suitability

\begin{tabular}{llll}
\hline Management level & Average & Standard deviation & 95\% Confidence interval \\
\hline Primitive & 0.1566 & 0.00067 & $0.1553-0.1579$ \\
Pre-development & 0.2658 & 0.00128 & $0.2633-0.2683$ \\
Developed & 0.2358 & 0.00156 & $0.2328-0.2389$ \\
\hline
\end{tabular}

Settler allocation and technical support

Machadinho settlers were mostly migrants (mainly from the Southern region), some with previous agricultural experience, but most with no knowledge of agricultural potential or techniques necessary for farming in a tropical rain forest area. They were poor people attracted by cheap land and promised government support (Browder and Godfrey 1997; Moran 1981; Wood and Carvalho 1988). Individual allocation of plots in Machadinho did not follow a rational procedure aimed at maximizing the potential for success in agricultural practices, despite attempts from the Instituto Nacional de Colonização e Reforma Agrária-INCRA (National Institute for Colonization and Agrarian Reform) to schedule interviews with settlers before the assignment of plots. The purpose of these interviews was to investigate the crops they had produced in the past, in order to place settlers in plots that would maximize their returns, based on the soil surveys. The initiative, however, was compromised by the massive influx of migrants to the area, by the shortage of personnel to conduct the interviews, and by the fact that some settlers preferred to be placed close to friends' plots, regardless of the agricultural suitability (J. L. Oliveira, June 2001, personal communication).

In addition, there is no indication that settlers had good access to technical information: 43\% of settlers did not receive technical assistance in 1986 from Empresa de Assistência Técnica e Extensão Rural_EMATER (Technical Assistance and Rural Extension Enterprise), and in 1989, this number increased to 72\%. Also, only $11 \%$ visited the local agency of Empresa Brasileira de Pesquisa Agropecuária-EMBRAPA (Brazilian Agricultural Research Corporation) (Miranda 1987; Miranda and Mattos 1993). In 2002, 23\% of farmers interviewed still listed the lack of adequate knowledge of soil characteristics and poor soil fertility as one of the main limiting factors for agriculture production (Mangabeira et al. 2005). Moreover, ethnographic assessments conducted in 1985-1987 revealed that a "common-knowledge" soil map, shown in Fig. 3, was used locally to inform and advise settlers. We do not have information on which, and how many farmers did have access to this information. However, compared to Fig. 3, this classification has minimum overlap with the real soil information at any management level, even if the information in Fig. 3 was smoothed in order to assign a single class to each plot. The map in Fig. 3 fails to portray the heterogeneity in soil quality and does not indicate any unsuitable areas for agriculture.

Although INCRA had well-defined rules for plot occupation and land tenure, some settlers did not physically live on the plot. Household surveys conducted in Machadinho at the onset of the project and 1, 2 and 10 years after its 


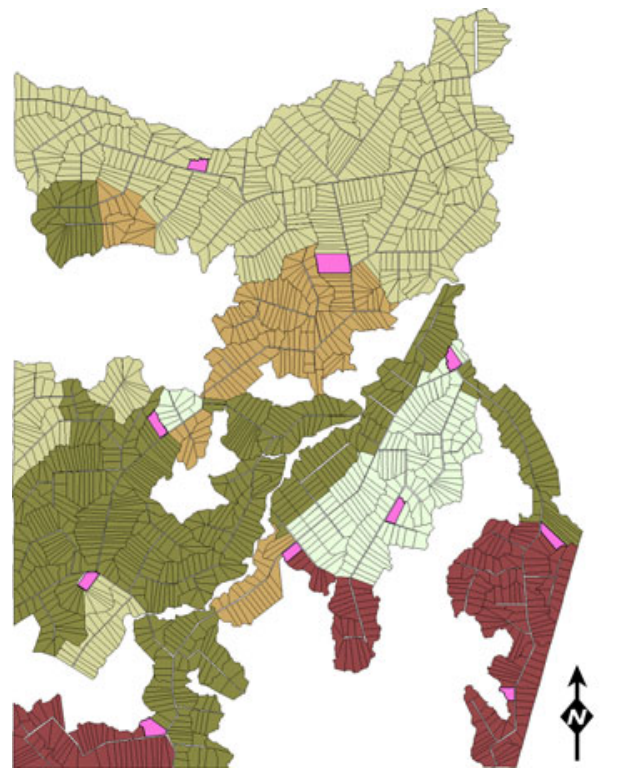

\section{Perceived soil quality ("common-knowledge")

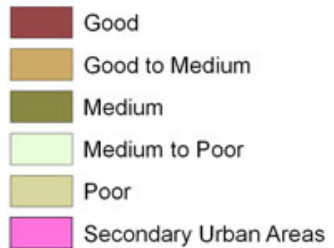

Source: Etnographic assessment, 1985-7

Notes:

1. Secondary urban areas were expected to provide local services, and were not assigned to settler for occupation.

2. Color coding for classes Good, Medium, and Poor match those used in Figure 2 for classes Good, Medium, and Restricted, respectively.

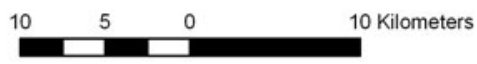

Fig. 3 Soil quality in Machadinho, Tracts 1 and 2, as perceived locally

commencement revealed that approximately 16, 31, 43 and 55\% of the plots were effectively occupied in 1985, 1986, 1987, and 1995, respectively. In addition, land turnover among settlers was very common (Campari 2002; Martine 1990; Moran 1993): $23.7 \%$ of settlers interviewed in 1985 were not living in the area in 1986 (Torres 1987), and until 2001, only $29 \%$ of plots had only one owner, according to official records (Castro 2002). However, this percentage was likely to be even lower due to a lack of systematic surveillance of plot occupation and the occurrence of illegal land transactions. Comparing plot occupancy observed during the household surveys conducted in Machadinho with soil limitations and elevation, significant correlations were observed. For example, plot occupancy in each of the survey years was negatively correlated with plots that had soils with fertility and oxygen deficiency (Spearman correlation coefficient was -0.06 in $1985, p=0.0183 ;-0.15$ in $1986, p<0.0001 ;-0.12$ in $1987, p<0.0001$; and -0.07 in $1995, p=0.0038$ ). Regarding elevation, the larger the area of the plot that is flat, the higher the occupancy in 1986 (Spearman's correlation coefficient $=0.12, p<0.0001$ ).

The clearing process: are better soils used first?

Table 4 shows information on the cleared area in each plot, matched with the information of agricultural suitability at the primitive management level (Fig. 2). At this management level, less than $1 \%$ of the area in Machadinho presented good agricultural suitability, all located in Tract 2 . Yet, only one tenth and slightly more than half of those areas had been cleared of the forest cover in 1985 and 1994, respectively. Soils with medium agriculture suitability were present in a small 
Table 4 Percent distribution of total and cleared area by agriculture suitability evaluated at the primitive management level, Machadinho, 1985 and 1994

\begin{tabular}{|c|c|c|c|c|c|c|c|c|c|}
\hline \multirow{3}{*}{$\begin{array}{l}\text { Agriculture suitability } \\
\text { at the primitive } \\
\text { management level }\end{array}$} & \multicolumn{3}{|c|}{$\%$ of area } & \multicolumn{6}{|c|}{$\%$ of area cleared in each soil attribute } \\
\hline & \multirow[t]{2}{*}{ Total } & \multirow[t]{2}{*}{ Tract 1} & \multirow[t]{2}{*}{ Tract 2} & \multicolumn{2}{|l|}{ Total } & \multicolumn{2}{|c|}{ Tract 1} & \multicolumn{2}{|c|}{ Tract 2} \\
\hline & & & & 1985 & 1994 & 1985 & 1994 & 1985 & 1994 \\
\hline Good & 0.98 & - & 1.51 & 10.07 & 52.49 & - & - & 10.07 & 52.49 \\
\hline Medium & 4.47 & 12.71 & - & 6.64 & 43.80 & 6.64 & 43.80 & - & - \\
\hline Restricted & 93.34 & 86.10 & 97.26 & 5.47 & 37.24 & 3.71 & 30.64 & 6.31 & 40.41 \\
\hline Unsuitable & 1.21 & 1.19 & 1.23 & 8.12 & 40.26 & 6.43 & 33.24 & 9.01 & 43.93 \\
\hline
\end{tabular}

fraction of the area (4.47\%), and less than half of them had been utilized until 1994. Approximately 30 and $40 \%$ of areas with restricted agriculture potentialthe most frequent type of suitability at a primitive level, have been utilized in 1994 in Tracts 1 and 2, respectively. Regarding soils not appropriate for agriculture, 8 and $40 \%$ of their area was cleared in 1985 and 1994, respectively. Of those plots that were designated as unsuitable for agriculture, only $36 \%$ had the same owner between 1985 and 2001, and 20\% had more than one fifth of the area used for pasture.

The panels shown in Fig. 4 help to illustrate the clearing process. Panel 1 shows six plots that contained a mix of good, restricted, and unsuitable soils. No patch of the latter had been cleared until 1994, since they were located at the rear of the plots. Not all good soils had been used by farmers, although all used at least some patches closer to the road. Particularly, the plot in the farthest right corner shows that soils with good quality were left intact while restricted soils in the interior of the plot were cleared. In contrast, Panel 2 shows a plot where good soils were located in the middle of the plot, and most of the land clearing was concentrated close to the road, where restricted soils prevailed. With all other conditions held the same, farmers in the second panel would have lower chances to succeed compared to those in Panel 1.

Panels 3 and 4 contrast plots with soils unsuitable for agriculture production. In the former, these soils were close to the road. All clearing done in 1985 was in that type of soil, and by 1994, most of the unsuitable area had been cleared. Also, 36\% of the area of the plots was covered with pasture in 1995, as reported by the settlers. In contrast, unsuitable soils were located in the rear of the plots shown in Panel 4, and until 1994, they had not been used by farmers. Similar to the previous example, a combination of chance and lack of information could make some farmers better off, assuming that all other conditions were the same.

Finally, Panel 5 shows an example where plots had a unique type of soil: restricted. In this case, the lack of information does not impact decisions of where to clear/plant, but impact those related to what crops should be produced, considering low use of inputs. According to the 1995 household survey, $31 \%$ of the area of each plot shown in Panel 5 was covered with pasture, as reported by the settler. In both plots, however, the current settler was not the first owner. 


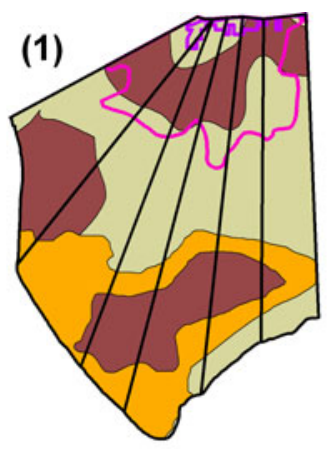

(2)
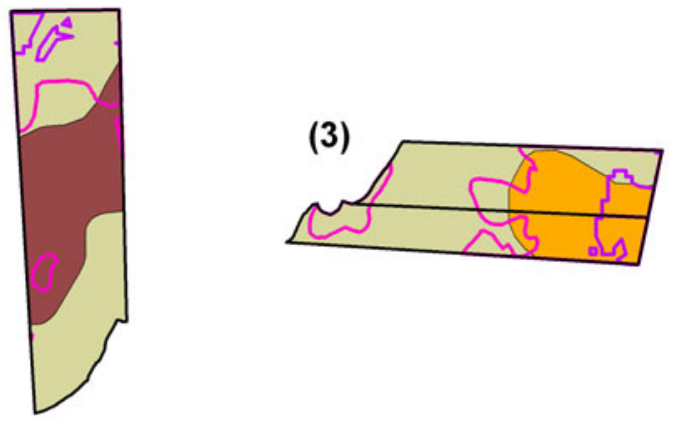

\section{(4)}
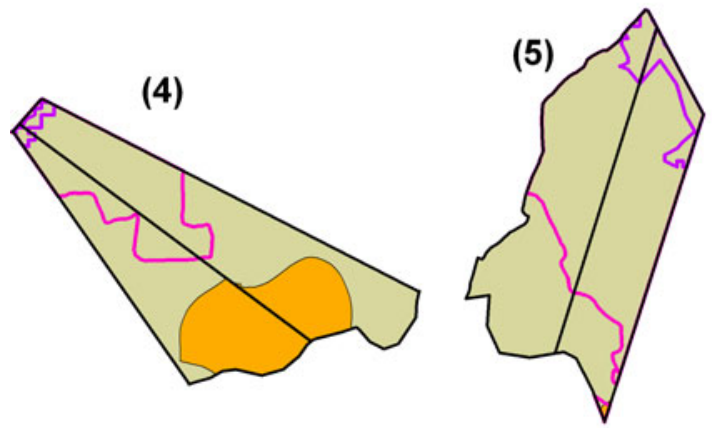

Extent of cleared area

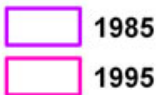

Agricultural Capability

Primitive Level

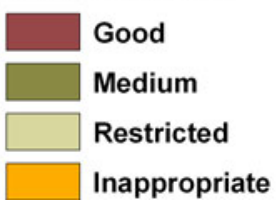

Fig. 4 Soil quality and land clearing in selected plots, Machadinho

Land use: management level and land suitability

In a simplified scenario, one could assume that farmers face three main questions upon arrival in a new settlement: Where to plant? Which crops to plant? How to plant? The first two questions could be better addressed if adequate information was available and provided by the government during the implementation phase. The last question refers to the level of management farmers will be able to afford. In a scenario where the vast majority of settlers were poor, and thus utilizing a primitive type of management, information was crucial.

Considering the recommendation of crops shown in Table 3, 1\% of plots occupied in 1985 had rubber trees, and 13\% were producing cocoa; in 1995, these numbers rose to 23 and $24 \%$, respectively. The majority of plots were producing coffee in 1995, 86\%, which became the most important crop in the area. The quality of coffee was below the national average, but cultivation progressively gained in importance, as a consequence of a municipal government incentive (Millikan 1996). Both coffee and cocoa were not the recommended crops at a primitive level of management. The former demanded deep, well-drained, and non-sandy soils, while the latter needed soils with high nutrient levels (Wittern and Conceição 1982).

Most plots had a combination of crops recommended for different levels. During the first year of the settlement (1985), 86\% of the plots had at least one of the crops recommended for a primitive level of management and $51 \%$ were cultivating crops 
recommended for a developed level. The latter decreased to $45 \%$ in 1995, although this number was not significantly different from that observed in 1985. Plots with a combination of crops recommended for primitive and pre-development levels of management were the most common ( $92 \%$ of the plots in 1995).

On average, each plot had 6.8 ha under cultivation in 1986, 8.9 ha in 1989, 6.8 ha in 2002, and 5.9 ha in 2005. This decline in cultivated areas was accompanied by an increase in areas utilized for pasture, although this was not an originally recommended use for the land (Wittern and Conceição 1982): 1.1 ha in 1986, 2.8 ha in 1989, 21 ha in 2002, and 23.9 ha in 2005 (Grego et al. 2007). Pasture is positively correlated with flat soils (Spearman's correlation coefficient $=0.12$ in $1995, p=0.0003$ ), mostly located in the northeastern corner of Machadinho (Fig. 2). Although different mechanisms can result in use of land for pasture (Browder 2002), some may contribute to concentration of land (Amaral 2007), which compromises the achievement of effective agrarian reform.

Regarding inputs used by the farmers, only 28.6 and $33.5 \%$ of the settlers had a chainsaw in 1985 and 1986, respectively. In 1995, 9.4\% of farmers in Tracts 1 and 2 requested a bank loan for agriculture, and only $1.2 \%$ requested a bank loan to buy agricultural equipments (Castro 2002). Those numbers and the evidence that settlers did not have access to detailed technical information, corroborate the hypothesis that a primitive management level was largely used. This was supported by the results of the first Agrarian Reform Census: in Rondônia, 49\% of settlers had no access to technical assistance, only $3 \%$ used inputs to improve the soil, and only $7 \%$ used any type of mechanization (Incra/Crub/UnB 1997b).

\section{Discussion}

The implementation of agricultural settlement projects, as part of a national effort to promote agrarian reform, resulted in positive and negative outcomes from a social and environmental perspective. Specifically, the majority of projects were planned and implemented without proper information to comprehensively assess feasibility, agricultural capability, carrying capacity, and market opportunities for production. Poor soil fertility, isolation from main markets, precarious technical support, and lack of credit to farmers are some of the conditions that can compromise the successful implementation and development of settlement areas.

Using Machadinho as an example, our results showed that the average quality of the soil was low and agricultural suitability restricted. The average low fertility of soils in Machadinho was also highlighted in a comparative assessment of agriculture projects implemented in Rondônia between 1970 and 1985 (Fearnside 1986b). While seven projects implemented between 1970 and 1978 had $42.1 \%$ of the area consisted of good soils for agriculture at a primitive level of management, only $7.2 \%$ of the Machadinho area had the same soil capability. The majority of soils in Machadinho, 57.8\%, were found to be good only if a developed level of management was used; in the remaining projects, they amounted to only $13.8 \%$. Machadinho also presented one of the highest percentages of soils unsuitable for 
agricultural purposes, $27.7 \%$ (Fearnside 1986b), most assigned as protected forest reserves.

Most settlers had no access to knowledge about agricultural capability of the area, did not receive technical information, had no means to afford the use of agricultural inputs, planted inadequate crops, and did not manage to stay in the plot for a long period of time. About two-thirds of farmers initially assigned to Machadinho had left 15 years after Machadinho was opened. The percentage of land dedicated to pasture has been increasing in Machadinho (Grego et al. 2007) and is often connected to ownership of multiple plots by one single person (Amaral 2007). Land concentration in Machadinho was also reported by the first Agrarian Reform Census, with an extreme case of 36 plots owned by the same person (Incra/ Crub/Unb 1997a), and land concentration was also observed in other areas in the Amazon (Campari 2002; Incra/Crub/Unb 1997a; Ludewigs and Brondízio 2005). An analysis of the 1995-1996 Agrarian Census revealed that $41.5 \%$ of the area assigned to agricultural establishments in the Amazon remained as native forest, and $55 \%$ was agricultural land; however, more than three-quarters of the agricultural land was being used as pasture (Chomitz and Thomas 2001).

According to official numbers, 35,222 families have settled in projects implemented in Rondônia up to 2007 , which is only $47 \%$ of the estimated number of families targeted to be settled in the state (MDA/INCRA/DTI 2007). However, the number of settled families is likely to be overestimated-during the first Agrarian Reform Census no families were found in six settlement projects in Rondônia, and a huge disparity between official records and census data was reported (Incra/Crub/Unb 1997a). Five of these six projects were located in the area of the two tracts not included in Machadinho due to poor soil quality, as previously mentioned. The area was progressively invaded, but had no infrastructure and, in response to major social problems, INCRA started to legalize the occupations in 1995 through the creation of six new settlement projects (J. L. Oliveira, June 2001, personal communication).

This process of invasion, and later legalization, highlights problems in the current Brazilian legislation regarding land ownership, which contribute to increased deforestation and land conflicts (Alston et al. 2000; Fearnside 2003; Hecht and Cockburn 1989; Kirby et al. 2006). Squatters who invade an area and prove that the land is being effectively developed may eventually secure land ownership. According to the legislation, conversion into pasture is one way to effectively use the land (Fearnside 1985). Also, some of the squatters are former settlers selected for government sponsored agricultural settlements who abandoned or sold (unlawfully) their plots. Any financial aid they received at the time of occupation is linked to the plot, not to themselves, which provides an extra incentive to abandon a plot after the money is received (Fearnside 2003). Legally, those farmers should not be assigned to any other settlement project. However, although in the recent years, INCRA has improved the database of settlers benefitting from the agrarian reform program, a comprehensive and updated system that allows INCRA to track down farmers who abandoned or sold their plots, to remove them as candidates for future settlements, and to assure that initial loans are properly paid is yet to become operational. 
A framework for conducting thorough evaluations during the planning phase of settlement projects is available. The Land Resource Information and Suitability System for Family Agriculture (LARISSA) is an expert system developed to assist evaluation and decision making, which combines qualitative and quantitative information on local physical attributes and socio-economic characteristics (Sparovek 2002). Such an expert system could dramatically improve the overall suitability of new agricultural settlements. Although the system was expected to be implemented by INCRA, it has not been incorporated in the decision making process regarding settlement projects. Also, the usefulness of the expert system in invasion areas is limited, since, as highlighted before, no effective planning is undertaken in such situations.

Better planning would contribute to successful farmer outcomes in the early years of occupation, to decrease the likelihood of plot turnover, but also to reduce the costs of the agrarian reform program. Currently, the government can expropriate areas for agrarian reform, which are paid with agrarian debt bonds. When areas with restricted agricultural capability are acquired (such as Machadinho), the final cost surpasses initial estimations if one considers the social and environmental burdens likely to be operative. Proper planning would prevent the government from spending money on unsuitable lands, and in varied programs required to address social and environmental problems created due to occupation of those areas. Yet, ideal planning and implementation of a new settlement area does not guarantee complete success, since other factors, and the interactions among them, can modify initial conditions (Wood 2002).

Also important are the demographic and socioeconomic contexts of settlement areas. As Moran (1989a, b) proposed, during the first 5 years of the settlement process, settlers tend to reproduce their previous farming knowledge, learning-andadapting through practice. Taking Machadinho as an example, the majority of settlers were migrant farmers from the South region of Brazil (Castro 2002), who were used to different types of soil, different agricultural practices, and different strategies of land management. In addition, since they had limited resources, hiring labor to work the land and acquiring inputs to improve the fertility of the soil were not common. Moreover, about a third of families were incomplete in the early years occupation of Machadinho (Sawyer and Sawyer 1987), so family labor was also limited. Therefore, the learning-and-adapting process faced challenges that were most likely augmented by the poor technical support and below average soil quality. Feedback effects in this process include the fact that the use of inadequate agriculture practices could lead to soil degradation, nutrition imbalance and loss of organic matter (Goodland 1980), thus making soil quality even worse. Ultimately, succeeding in a settlement process depends on settlers' characteristics, on the local conditions, and on the context in which the two interact and transform each other (Sawyer and Sawyer 1987).

In addition to potential economic consequences, soil inadequacies are likely to have fostered more extensive malaria transmission than might have occurred in the presence of optimal matching of soils to settler farming capabilities. In the case of Machadinho, we did observe a significant and negative correlation between malaria and flat soils, where most cattle production takes place. Indeed, clusters of low 
malaria rates were observed in these areas since the early years of occupation in Machadinho (Castro et al. 2006). In addition, we observed a significant and positive correlation between malaria and plots that would have a better index of agricultural suitability if settlers were able to afford a pre-development or developed level of management. A significant and negative correlation was found between malaria and plots whose index of agricultural suitability would remain unchanged regardless of the management level. This is an overlooked linkage to disease outbreaks, which provides further motivation for future research and new policies at the land usehealth interface.

The issues here discussed exemplify how development strategies planned for the Amazon operate without proper knowledge of the region's challenges, resources, and capabilities (Becker 2001). They also exemplify many of the subtle details at the population-environment interface that Daniel Hogan worked so hard to move into the demographic mainstream (Hogan 1995). Poorly planned and implemented agricultural settlements are likely to defy the main purpose of agrarian reform initiatives, resulting in significant environmental and socioeconomic burdens. The former is the burden of increased deforestation. It exposes soils with poor nutrient levels, which are unlikely to sustain farming in the long-run (eventually resulting in areas of secondary succession) and creates the need to clear new areas. The latter imposes a burden on settlers, who move in with poor resources and are often forced to move out due to a combination of unfortunate events-e.g., debts, failed crops, and illness (that could have been mitigated), and end up occupying other areas without any infrastructure. The entire process generates a vicious cycle that penalizes the poor, favors the rich, and puts pressure on the environment. Without proper government willingness and commitment, adequate financial and human resources, and effective law enforcement, it is unlikely that this vicious cycle can be broken and a successful agrarian reform achieved.

Acknowledgments The authors are grateful to Josefa Ávila for her invaluable support in contacting government institutions in Brasília in order to obtain the soil surveys for Tract 1 of Machadinho; to William Guthe, GIS and Remote Sensing Coordinator at Princeton University, who provided support digitizing the soil quality maps; to Roberto Monte-Mór, for invaluable discussions regarding Machadinho ethnography; and to two anonymous reviewers for their helpful comments. MCC thanks the Department of Global Health and Population, Harvard School of Public Health for financial support.

Open Access This article is distributed under the terms of the Creative Commons Attribution Noncommercial License which permits any noncommercial use, distribution, and reproduction in any medium, provided the original author(s) and source are credited.

\section{References}

Almeida, A. L. O. (1992). The colonization of the Amazon. Austin: University of Texas Press.

Alston, L. J., Libecap, G. D., \& Mueller, B. (2000). Land reform policies, the sources of violent conflict, and implications for deforestation in the Brazilian Amazon. Journal of Environmental Economics and Management, 39, 162-188.

Amaral, J. J. O. (2007). Os Latifúndios do INCRA. Porto Velho, RO: EDUFRO—Editora da Universidade Federal de Rondônia. 
Araújo, F. C. (2006). Reforma Agrária e Gestão Ambiental: Encontros e Desencontros (p. 293). Brasília: Centro de Desenvolvimento Sustentável, Universidade de Brasília (UnB).

Becker, B. K. (2001). Revisão das políticas de ocupação da Amazônia: é possível identificar modelos para projetar cenários? Parcerias Estratégicas, 12, 135-159.

Benchimol, S. (1985). Population changes in the Brazilian Amazon. In J. Hemming (Ed.), Change in the Amazon basin (pp. 37-50). Manchester: Manchester University Press.

Brondízio, E. S., McCracken, S. D., Moran, E. F., Siqueira, A. D., Nelson, D. R., \& Rodriguez-Pedraza, C. (2002). The colonist footprint: Toward a conceptual framework of land use and deforestation trajectories among small farmers in the Amazonian frontier. In C. H. Wood \& R. Porro (Eds.), Deforestation and land use in the Amazon (pp. 133-161). Gainesville: University Press of Florida.

Browder, J. O. (2002). Reading colonist landscapes: Social factors influencing land use decisions by small farmers in the Brazilian Amazon. In C. H. Wood \& R. Porro (Eds.), Deforestation and land use in the Amazon (pp. 218-240). Gainesville: University Press of Florida.

Browder, J. O., \& Godfrey, B. J. (1997). Rainforest cities: Urbanization, development, and globalization of the Brazilian Amazon. New York: Columbia University Press.

Campari, J. S. (2002). Challenging the turnover hypothesis of Amazon deforestation: Evidence from colonization projects in Brazil. Austin: Department of Economics, The University of Texas at Austin.

Castro, M. C. (2002). Spatial configuration of malaria risk on the Amazon frontier: The hidden reality behind global analysis (p. 293). Princeton: Office of Population Research, Princeton University.

Castro, M. C., Sawyer, D. O., \& Singer, B. H. (2006). Spatial patterns of malaria in the Amazon: Implications for surveillance and targeted interventions. Health \& Place, 13, 368-380.

Chomitz, K. M., \& Thomas, T. S. (2001). Geographic patterns of land use and land intensity in the Brazilian Amazon (p. 41). Development Research Group, World Bank.

Cliggett, L., Colson, E., Hay, R., Scudder, T., \& Unruh, J. (2007). Chronic uncertainty and momentary opportunity: A half century of adaptation among Zambia's Gwembe Tonga. Human Ecology, 35, 19-31.

Cochrane, T. T., \& Sanchez, P. A. (1982). Land resources, soils and their management in the Amazon region: A state of knowledge report. In S. B. Hecht (Ed.), Amazonia, agriculture and land use research: Proceedings of the international conference (pp. 137-209). Cali, Colombia: Centro International de Agriculture Tropical-CIAT.

Fearnside, P. M. (1985). Agriculture in Amazonia. In G. T. Prance \& T. E. Lovejoy (Eds.), Amazonia (key environments) (pp. 393-418). Oxford; New York: Pergamon Press.

Fearnside, P. M. (1986a). Human carrying capacity of the Brazilian rainforest. New York: Columbia University Press.

Fearnside, P. M. (1986b). Settlement in Rondônia and the token role of science and technology in Brazil's Amazonian development planning. Interciencia, 11, 229-236.

Fearnside, P. M. (1989). A ocupação humana de Rondônia: impactos, limites e planejamento. Brasília: SCT/PR-CNPq, Assessoria Editorial e Divulgação Científica.

Fearnside, P. M. (2003). Questôes de posse da terra como fatores na destruição ambiental na Amazônia brasileira: o caso do sul do Pará. (p. 22). Instituto Nacional de Pesquisas da Amazônia (INPA).

Goodland, R. (1980). Environmental ranking of Amazonian development projects in Brazil. Environmental Conservation, 7, 9-26.

Grego, C. R., Miranda, E. E., Valladares, G. S., Custódio, D. O., Franzin, J. P., \& Silva, C. F. (2007). Análise exploratória e dinâmica espacial e temporal dos sistemas de produção em Machadinho $d^{\prime}$ Oeste (RO), entre 1986 e 2005. Campinas, SP: Embrapa Monitoramento por Satélite. Documentos, 64.

Guanziroli, C., Bittencourt, G. A., Castilhos, D. S. B., Bianchini, V., \& Silva, H. B. C. (1999). Principais Fatores que Afetam o Desenvolvimento dos Assentamentos de Reforma Agrária no Brasil. Projeto de Cooperação Técnica Incra/FAO (p. 62). Brasília: INCRA/FAO.

Hecht, S. B., \& Cockburn, A. (1989). The fate of the forest: Developers, destroyers, and defenders of the Amazon. London; New York: Verso.

Hogan, D. J. (1992). The impact of population growth on the physical environment. European Journal of Population, 8, 109-123.

Hogan, D. J. (1995). Population and environment in Brazil: A changing agenda. In J. I. Clarke \& L. Tabah (Eds.), Population-environment-development interactions (pp. 245-252). Paris: CICRED.

Hogan, D. J. (2005). Mobilidade populacional, sustentabilidade ambiental e vulnerabilidade social. Revista Brasileira de Estudos Populacionais, 22, 323-338. 
Hogan, D. J. (2007). Human dimensions of global environmental change. Revista Ambiente e Sociedade, $10,161-166$.

Hogan, D. J. (2009). Demographic dynamics and sustainability in Brazil. In L. E. Sanchez (Ed.), Encyclopedia of Life Support Systems (EOLSS). Area studies-Brazil (regional sustainable development review) (pp. 57-85). UNESCO-EOLSS.

Hogan, D. J., Berquo, E., \& Costa, H. S. M. (2002). Population and environment in Brazil: Rio + 10. Campinas: CNPD/ABEP/NEPO.

Hogan, D. J., \& Ojima, R. (2008). Urban sprawl: A challenge for sustainability. In G. Martine, G. McGranahan, M. Montgomery, \& R. Fernández-Castilla (Eds.), The new global frontier: Urbanization, poverty and environment in the 21st century (pp. 203-216). London: Routledge.

INCRA. (1991). Exposição de Motivos. Brasília: INCRA/SE-17/G/NO. 02/91.

Incra/Crub/Unb. (1997a). Dossiê questão agrária: I Censo da Reforma Agrária. Estudos Avançados, 11, 7-36.

Incra/Crub/UnB. (1997b). I Censo da Reforma Agrária do Brasil. Brasília: DF: Instituto Nacional de Colonização e Reforma Agrária-INCRA.

Jordan, C. F. (1985). Soil of the Amazon rainforest. In G. T. Prance \& T. E. Lovejoy (Eds.), Amazonia (key environments) (pp. 83-94). Oxford; New York: Pergamon Press.

Kirby, K. R., Laurance, W. F., Albernaz, A. K., Schroth, G., Fearnside, P. M., Bergen, S., et al. (2006). The future of deforestation in the Brazilian Amazon. Futures, 38, 432-453.

Ludewigs, T., \& Brondízio, E. S. (2005). Integrating remote sensing, GIS and field surveys: the study of lot turnover, land concentration and land use in colonization areas. XII Simpósio Brasileiro de Sensoriamento Remoto (pp. 3535-3542). Goiânia, GO: INPE.

Mangabeira, J. A. C., Miranda, E. E., \& Gomes, E. G. (2005). Perfil Agrossocioeconômico dos Produtores Rurais de Machadinho d'Oeste (RO), em 2002. Campinas, SP: Embrapa Monitoramento por Satélite. Documentos, 38.

Martine, G. (1990). Rondônia and the fate of small producers. In D. Goodman \& A. L. Hall (Eds.), The future of Amazonia: Destruction or sustainable development? (pp. 23-48). Houndmills, Basingstoke, Hampshire: The Macmillan Press.

McCracken, S. D., Siqueira, A. D., Moran, E. F., \& Brondízio, E. S. (2002). Land use patterns on an agricultural frontier in Brazil: Insights and examples from a demographic perspective. In C. H. Wood \& R. Porro (Eds.), Deforestation and land use in the Amazon (pp. 162-192). Gainesville: University Press of Florida.

MDA/INCRA/DTI. (2007). Projetos de Reforma Ágrária Conforme Fases de Implementação-Período da Criação do Projeto: 01/01/1900 até 05/10/2007. Brasília: Ministério do Desenvolvimento Agrário-MDA; Instituto Nacional de Colonização e Reforma Agrária-INCRA; Diretoria de Obtenção de Terras e Implantação de Projetos de Assentamento-DT; Coordenação-Geral de Implantação-DTI-Sipra.

Millikan, B. (1996). Frontier expansion, environmental change and malaria transmission in Machadinho d'Oeste. Rondônia, Brazil (mimeo).

Miranda, E. E. (1987). Rondônia: a terra do mito e o mito da terra-os colonos do Projeto Machadinho. Porto Velho: EMBRAPA.

Miranda, E. E., \& Mattos, C. (1993). De colonos a munícipes na floresta tropical de RondôniaMachadinho d'Oeste. Campinas, SP: ECOFORÇA/EMBRAPA-NMA.

Monte-Mór, R. L. (1997). Urban and rural planning: Impact on health and the environment. In G. S. Shahi, B. S. Levy, A. Binger, T. Kjellstrom, \& R. Lawrence (Eds.), International perspectives on environment, development, and health: Toward a sustainable world (pp. 554-566). New York: Springer.

Moran, E. F. (1981). Developing the Amazon. Bloomington: Indiana University Press.

Moran, E. F. (1989a). Adaptation and maladaptation in newly settled areas. In D. A. Schumann \& W. L. Partridge (Eds.), The human ecology of tropical land settlement in Latin America. Boulder, CO: Westview Press.

Moran, E. F. (1989b). Government-directed settlement in the 1970s: An assessment of Transamazon Highway Colonization. In D. A. Schumann \& W. L. Partridge (Eds.), The human ecology of tropical land settlement in Latin America. Boulder, CO: Westview Press.

Moran, E. F. (1990). Private and public colonization schemes in Amazonia. In D. Goodman \& A. L. Hall (Eds.), The future of Amazonia: Destruction or sustainable development? (pp. 70-89). Houndmills, Basingstoke, Hampshire: The Macmillan Press. 
Moran, E. F. (1993). Through Amazonian eyes: The human ecology of Amazonian populations. Iowa City: University of Iowa Press.

Moran, E. F., Brondízio, E. S., \& McCracken, S. D. (2002). Trajectories of land use: Soils, succession, and crop choice. In C. H. Wood \& R. Porro (Eds.), Deforestation and land use in the Amazon (pp. 193-217). Gainesville: University Press of Florida.

Muchagata, M., \& Brown, K. (2000). Colonist farmers' perceptions of fertility and the frontier environment in eastern Amazonia. Agriculture and Human Values, 17, 371-384.

RADAMBRASIL. (1978). Levantamento de recursos naturais: geologia, geomorfologia, pedologia, vegetação, uso potencial da terra. Rio de Janeiro: Projeto Radambrasil.

Salamon, L. M. (1979). The time dimension in policy evaluation: The case of the New Deal land-reform experiments. Public Policy, 27, 129-183.

Sawyer, D. R. (1985). Research design and feasibility in the Machadinho settlement project. Belo Horizonte: CEDEPLAR.

Sawyer, D. R., \& Sawyer, D. O. (1987). Malaria on the Amazon frontier: Economic and social aspects of transmission and control. Belo Horizonte: CEDEPLAR.

Scudder, T. (2006). The future of large dams: Dealing with social, environmental, institutional and political costs. London; Sterling, VA: Earthscan.

Sparovek, G. (2002). The Land Resource Information and Suitability System for Family Agriculture (LARISSA), developed for the Brazilian agrarian reform. Journal of Agriculture in the Tropics and Subtropics, 103, 47-59.

Sparovek, G. (2003). A Qualidade dos Assentamentos da Reforma Agrária Brasileira. São Paulo: Páginas \& Letras Editora e Gráfica.

Torres, H. G. (1987). Desistência e substituição de colonos em projetos de colonização de Rondônia: um estudo de caso. Belo Horizonte: CEDEPLAR.

Wittern, K. P., \& Conceição, M. (1982). Levantamento de reconhecimento de média intensidade dos solos e avaliação da aptidão agrícola das terras em 100,000 hectares da gleba Machadinho, no município de Ariquemes, Rondônia. Rio de Janeiro: EMBRAPA/SNLCS. Boletim de Pesquisa no. 16.

Wood, C. H. (2002). Introduction: Land use and deforestation in the Amazon. In C. H. Wood \& R. Porro (Eds.), Deforestation and land use in the Amazon (pp. 1-38). Gainesville: University Press of Florida.

Wood, C. H., \& Carvalho, J. A. M. (1988). The demography of inequality in Brazil. Cambridge; New York: Cambridge University Press.

World Bank. (1981). Brazil: Integrated development of the Northwest Frontier (p. 101). Washington, DC: The World Bank.

World Bank. (1992). World Bank approaches to the environment in Brazil: A review of selected projects (p. 344). Volume 5: The POLONOROESTE Program. Washington, DC: The World Bank. 